\title{
OOCYTE DEVELOPMENT AND ANNUAL CYCLE OF OVARIAN COMPOSITIONS IN THE REDBELLY YELLOWTAIL FUSILIER CAESIO CUNING (BLOCH) FROM THE KARIMUNJAWA WATERS
}

\author{
Endang Sri Susilo S. , $^{, *}$, Lilik Harnadi ${ }^{2,3}$ and Akihiro Takemura ${ }^{3}$ \\ ${ }^{1}$ Department of Marine Sciences, Diponegoro University, \\ Kampus Jurusan Ilmu Kelautan Tembalang, Semarang 50275, Indonesia \\ ${ }^{2}$ Present address: Marine and Fisheries Affairs, Government of Central Java, \\ Jl. Imam Bonjol 134 Semarang 50132, Indonesia \\ ${ }^{3}$ Sesoko Station, Tropical Biosphere Research Center, University of the Ryukyus, \\ 3422 Sesoko, Motobu, Okinawa 905-0227, Japan \\ *e-mail: iiksuselo@gmail.com
}

\begin{abstract}
Histological examination of gonad of female redbelly yellowtail fusilier Caesio cuning was carried out in order to describe the oocyte development and annual changes of ovarian composition. The oocyte development was devided into seven stages: peri-nucleolus (PN), oil-droplet (OD), primary yolk (PY), secondary yolk (SY), tertiary yolk (TY), migratory (M) and maturation (Mt) stages. The histological examination of ovarian composition showed that the fish had three peak spawning seasons: in June-July, October-November and February-March. Various kind of developing oocytes found in the same ovaries suggested multiple spawner and asynchronous type of ovarian dynamic.
\end{abstract}

Keywords: Fusilier, Gonadal development, Multiple spawner, Oocyte, Spawning season.

\section{INTRODUCTION}

Redbelly yellowtail fusilier Caesio cuning is non-migratory reef associated fish and distributed in Indo-West Pacific region, from Sri Lanka to Vanuatu and from southern Japan to northern Australia (Froese and Pauly, 2006). The important fisheries of this species have been developed in country in SE Asia region (Carpenter, 1988; Anonymous, 1996). Studies on reproduction in teleost have concentrated on species from temperate water (Macer, 1974; Forberg, 1982; Mayer et al., 1988) and have recently also been conducted on this species in the tropic area (Ferreira, 1993, Arara and Ntiba, 1997; Asoh, 2004), only few information of reproduction of the redbelly yellowtail fusilier. In term of the reproductive strategies, this species is spawner pelagic which produce numerous pelagic eggs (Carpenter, 1987). However no substantial information is available on the gonadal development, reproduction mode and spawning periods.

In this study we examined the monthly changes of ovarian composition of redbelly yellowtail fusilier C. cuning, sampled within March 2004 through February 2005 from the Karimunjawa archipelago, the Java Sea to show the developing stages of the oocytes, spawning season and spawning mode.

\section{MATERIALAND METHODS}

Adult fishes ranged from 57.9 to 419.9 gram body weight were purchased every month from fish holder in Jepara (Central Java, Indonesia) from March 2004 to February 2005. The fishes were captured from the Karimunjawa Islands waters 
(Fig. 1) by local one day fishing fishermen. At the fish holder the fish was stocked on ice for up to three days before selling. To estimate the capturing time, we did back calculation between one to three days before the purchasing.

The ovarian fragments were removed from fish, weighted to the nearest $0.1 \mathrm{~g}$ and fixed in a ten percent formaldehyde solution. The fixed ovaries were then dehydrated in ascending grades of ethanol $(70,80,95$ and $100 \%)$, cleared in benzene, embedded in paraffin, sectioned transversely at $7 \mu \mathrm{m}$, and stained with Delafield's haematoxylin and eosin. Sectioned and stained tissue was subsequently examined under a light microscope.

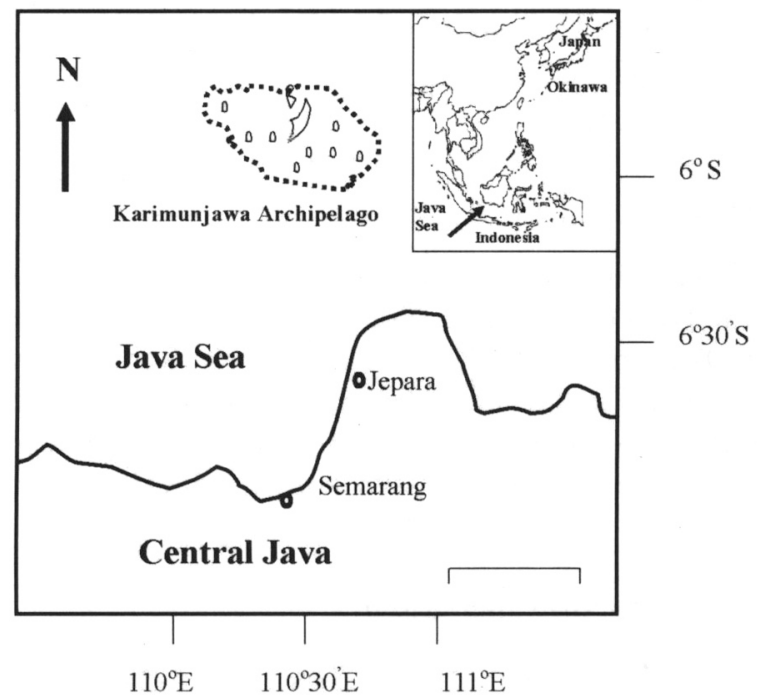

Figure 1. Map showing the position of Java Sea and Karimunjawa Archipelago in Central Java, Indonesia.

Developmental stages of oocytes were defined trough histological observation following several authors (Shirai, 1962; Yamamoto and Yoshioka, 1964; Forberg, 1982). Representative stages of oocyte development were photographed as well as oocyte composition in the ovary was determined by counting the number of oocytes at their respective stages under a light microscope.

Daily rainfalls and surface water temperatures data were obtained from Maritime Meteorological Station in Semarang, Central Java.

\section{RESULTS}

\section{Oocyte staging}

The oocyte development was devided into seven stages, based on histological observations, included: peri-nucleolus (PN), oil-droplet (OD), primary yolk (PY), secondary yolk (SY), tertiary yolk (TY), migratory (M) and maturation (Mt) stages. Atresia of the oocytes was also observed on several conditions from fresh to late as well as the empty follicle or post-ovulatory follicle (POF).

\section{Peri-nucleolus stage (PNS)}

The size of the oocytes in this stage was ranged from to $13-120 \mu \mathrm{m}$, while the $\mathrm{dk}$ was about 50 $60 \%$. The cytoplasm became strongly basophilic, whilst nucleus was weakly basophilic. Toward the end of this stage, the cytoplasm was decreased in basophilic and several nucleoli were situated in the periphery of the nucleus (Fig. 2a).

\section{Oil-droplet stage (ODS)}

The size of the oocyte in this stage was ranged from to $130-\mu \mathrm{m}$, while the $\mathrm{dk}$ decreased to $44-47$ $\%$. Oocytes had vesicles which appeared optically empty that gradually increase in size and number and were term oil droplets. In this stage oil droplets were distributed in a circular zone in the inner part of the cytoplasm (Fig. 2b). The follicle layer, zona radiata and vitelline envelope become visible. The zona radiata and follicle layer measure about 5 $\mu \mathrm{m}$ and $4 \mu \mathrm{m}$ respectively.

\section{Primary yolk stage (PYS)}

The diameter of the oocyte in this stage was range from 190 to $230 \mu \mathrm{m}$, while the $\mathrm{dk}$ was about $35 \%$. Various sizes of oil globules occupied a discrete zone around the nucleus. Yolk globules begin to appear as minute granules of eosinbasophilic, were accumulated mainly in the outer part of the cytoplasm. Nucleus membrane was not clear observed. Vitelline envelope became thicker about $10 \mu \mathrm{m}$ (Fig. 2c).

\section{Secondary yolk stage (SYS)}

The diameter of the oocyte in this stage was range from 280 to $370 \mu \mathrm{m}$, while the $\mathrm{dk}$ was about $25-35 \%$. The oil droplets had further enlarger and still occupied a discrete zone in the inner cytoplasm. The yolk globules became more eosinbasophilic, had multiple and increased in size as the oocytes growth, and accumulated in the outer two-thirds of the cytoplasm. The zona radiata had increased in thickness $(4 \mu \mathrm{m})$ as well as the follicle layer (Fig. 2d). 


\section{Tertiary yolk stage (TYS)}

Oocytes in this stage measured $290-430 \mu \mathrm{m}$ and the $\mathrm{dk}$ decreased from 25 to $13 \%$. The entire cytoplasm was filled with many yolk globules. The lipid droplets had migrated centripetally and interspersed between the yolk globules. During this stage second, less acidophilic, type of protein yolk granules appeared in the outer cytoplasm as a nonmembrane-bound amorphous mass. The zona radiata became thickener $(5 \mu \mathrm{m})$ than the previous stage (Fig. 2e).

\section{Migratory nucleus stage (MS)}

The diameter of oocyte may reached $540 \mu \mathrm{m}$. At this stage the nucleus migrated toward the micropyle as the animal pole (Fig. 2g). In this stage the yolk deposition was presumed stop (Arocha, 2002). The yolk globules and the oil droplets also started to coalesce. The coalesced yolk globules sometimes were less basophilic (Fig. 2f).

\section{Maturation stage (MtS)}

The oocyte rapidly increased in volume due to hydration, and reached $900 \mu \mathrm{m}$ in diameter. The

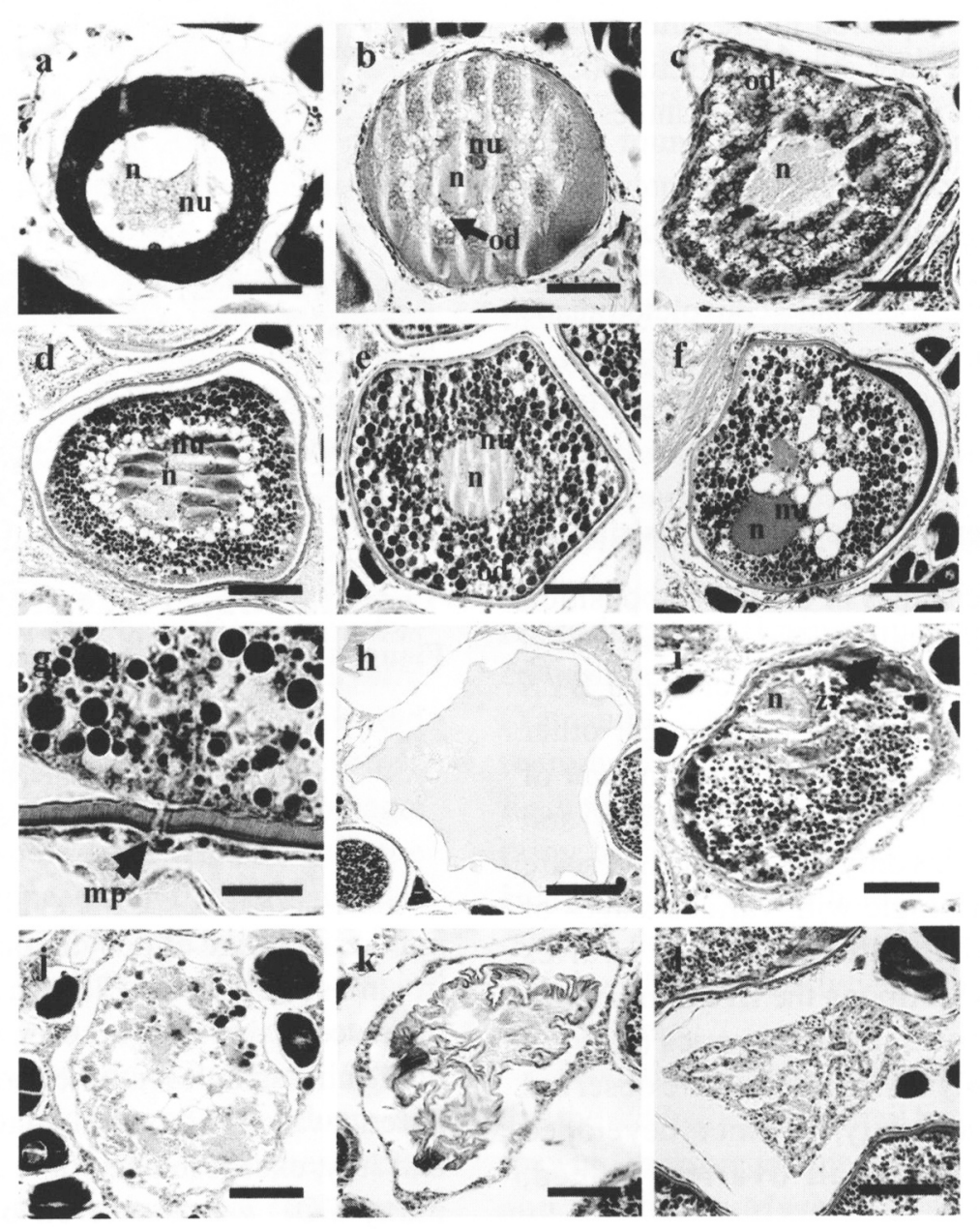

Figure 2. Histological appearance of redbelly yellowtail fusilier (Caesio cuning) oocytes. (a) Peri-nucleolus stage showing the position of the nucleoli at the periphery. (b) Oil-droplet stage oocyte showing oil droplet in the inner part of cytoplam. (c) Primary-yolk stage oocyte showing yolk granules in the periphery. (d) Secondary-yolk stage oocyte showing oil droplet concentrated in the perynuleolar. (e) Tertiary-yolk stage showing oil droplets intermingle with yolk globules in the cytoplasm. (f) Migratory stage oocyte showing nucleus migration to the animal pole. (g) Micropyle at the zona radiata as the animal pole. (h) Maturation stage oocyte . (i) atreasia of yolk stagee oocyte. Array showed the wrinkle zona radiata. (j) advance atresia showed a heap of cells with yellow granules. (k) Fresh POF. (l) Other appearance of fresh POF. $\mathrm{nu}=$ nucleolus, $\mathrm{n}=$ nucleus, $\mathrm{od}=$ oil droplet, $\mathrm{ygr}=$ yolk granule, $\mathrm{yg}=$ yolk globule, $\mathrm{mp}=$ micropile, $\mathrm{zr}=$ zona radiata. Bar scale: (a) $20 \mu \mathrm{m}$, (b) $60 \mu \mathrm{m}$, (c) $40 \mu \mathrm{m}$, (d) $90 \mu \mathrm{m}$, (e) $90 \mu \mathrm{m}$, (f) $110 \mu \mathrm{m}$, (g) $\mu \mathrm{m}$, (h) $170 \mu \mathrm{m}$, (i) $55 \mu \mathrm{m}$, (j) $70 \mu \mathrm{m}$, (k) $70 \mu \mathrm{m}$, (l) $60 \mu \mathrm{m}$. 
coalesced yolk and oil globules were less visible. The follicle thinned and stretched due to the rapid increasing volume. The zona radiata are still prominent. At the late of this stage the content of the oocytes looked homogenous and translucent (Fig. 2h).

\section{Atretic oocyte}

Many kind of atresia had been observed in the oocyte of SYS, TYS and MS. The nucleus of the oocyte loosed its regularity and seemed to be disintegrated. Zona radiata lose its tension and become wrinkled (Fig. 2i). Sometimes a thick colloidal substance appeared in the outer part of the atretic cell. The later stage of atretic oocyte fully contained cells with yellowish granules (Fig. 2j).

\section{Post-ovulatory follicle (POF)}

The new empty follicle had a convoluted shape with many folds and loops (Fig. 2k and Fig. 21). It appeared contained granular materials definite granulose cells.

\section{Monthly Changes of Oocyte composition}

The Monthly changes of oocyte composition of the redbelly yellowtail fusilier are represented graphically in Figure 3. In March even SYS $(8.38 \%)$ take in the highest percentage, other advance stages were also exist in the amount of $2.60 \%$ (PYS), $3.31 \%$ (TYS) and $5.04 \%$ (MS) and among the six samples only one sample had scare of fresh POF intermingle with various stages of oocytes. In April the three of eight ovaries contained only PNS. Among the five remind, MS oocytes were observed in three ovaries $(1.31 \%)$. Ovaries bearing only PNS oocytes ware observed in May. In June and July, advance developed oocytes were found in all ovaries, indeed,

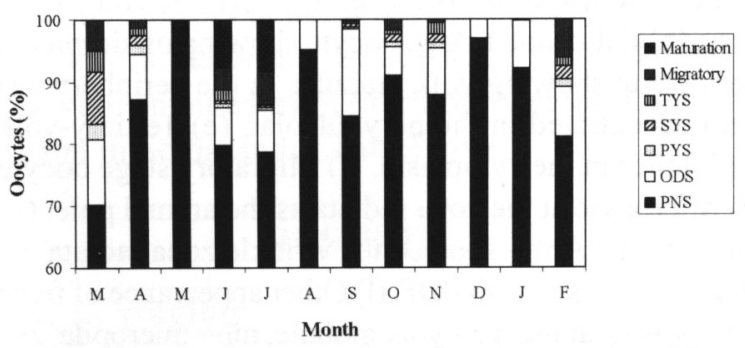

Figure 3. Monthly changes of oocyte compositions of redbelly yellowtail fusilier.

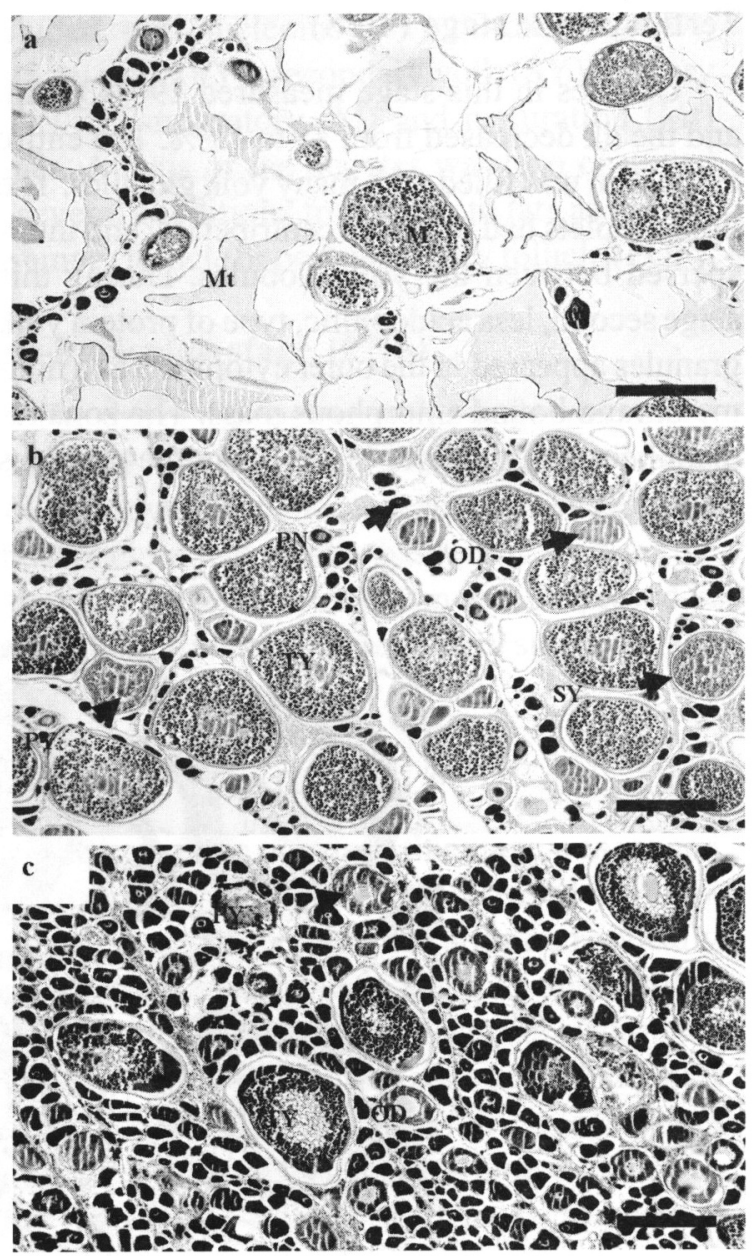

Figure 4. Histological appearance of the ovary of redbelly yellowtail fusilier.(a) Major spawning season in June-July. (b) Major spawning season in October-November (c) Minor spawning season. Bar scale $250 \mu \mathrm{m}$.

maturation stage of oocytes occupied large space in almost all ovaries (Fig. 4a). Some POF were observed in three of the seven samples and in one of the nine samples in June and July, respectively. Atretic was also found in all the samples of June and July, except in one of the June sample which many POF was scattered between the other developed oocytes. Early growth phase oocytes, PNS $(95.18 \%)$ and ODS $(4.82 \%)$, were found in August, as well as many POF and Atretic were observed in three and five of ten samples, respectively. In September almost all ovaries contented POF and atretic, however not all ovaries (four among nine) contained advance developed oocyted. In October (Fig. 4b) developed oocytes were also found in the relatively higher percentage compared to those in September. Moreover all ovaries contented advanced developed oocytes. 
In December and January, the ovaries were composed by early stages of oocytes. Almost all of the ovaries only in PNS with neither POF nor the atretic oocyte were observed in December. While in January, among the samples PYS and SYS were separately found in one ovary, POF was found in almost half of them, whilst atretic oocytes were found in almost all ovaries. In February developed ovaries appeared again in the percentage of $1.19 \%$ (PYS), $1.96 \%$ (SYS), $1.39 \%$ (TYS) and $6.26 \%(\mathrm{MS})$.

\section{DISCUSSION}

In the present study, oocytes undergo the same basic pattern of growth in other teleost species (Mayer et al., 1988; Arocha, 2002; Choi et al., 1996). PNS existed throughout the observation periods, suggesting that clusters of PNS of oocytes were always available for recruitment. ODS is later part of second growth phase (SPG) (Forberg, 1982). It is generally accepted that once SPG has started, spawning occurs within one year (Forberg, 1982). Therefore, in the redbelly yellowtail fusilier ODS can be considered as mark for starting of endogenous vitellogenesis. Yolk granule then appeared after in the oocyte periphery. It was the same as reported for the bass Dicentrarchus labrax (Mayer, et al., 1988), the bester, F1 hybrid sturgeon between beluga Huso husofemale and starlet Acipenser ruthenus male (Amiri, et al., 1996) and Tilapia zilii (Coward and Bromage, 1998). Whereas in some other teleost fishes the yolk granules first appeared in the perinucleolar cytoplasma (Forberg, 1982; Arocha, 2002). The appearance of yolk granules in the cytoplasm characterized the onset of endogenous vitellogenesis (Coward and Bromage, 1998). Vitellogenesis is the period of ovarian development when extraovarian proteins are sequestered, processed and packaged into oocytes (Tyler and Sumpter, 1996). The ability of oocyte to sequester vitellogenin, the principle of extraovarian protein, on reaching a certain critical size may be a function of the development of patency (Tyler et al., 1991). In producing buoyant eggs, vitellogenesis account for a smaller percentage of the final egg size (between $11 \%$ and $40 \%$ of the final egg size) than in species producing eggs that are oviposited on/into a substrate (reviewed by Tyler and Sumpter, 1996). In the present study, the size of the yolk stage oocytes account up to $46 \%$ of the final egg size, expressed the type of spawning mode that produce pelagic eggs.

Various kind of developing oocytes found in the same ovaries suggested multiple spawner and asynchronous type of ovarian dynamic, following Wallace (1981). This finding similar to those described for other species Caesio diagrama from Okinawan water, Japan (Choi et al., 1996) and some Lutjanus, the closet relative of this species (Arara and Ntiba, 1997; DeMartini and Lau, 1998; Jackson et al., 2006). The fish of this type usually having a comparatively long spawning period (Yamamoto and Yamasaki, 1961). In the present study, spawning period was investigated trough the presence of ODS as mark of initiation of endogenous vitellogenesis. ODS oocytes were mostly found throughout year. Resting ovaries which composed only PNS oocytes were observed in May and December, suggesting the off spawning season. Few resting oocytes found in April showed that some fishes had started the off spawning season since April. It subsequently proved by existence of POF in almost all the month observation except in April, May and December where it presence in ovaries is a certain evidence to prove that the fish have already experienced spawning (Yamamoto and Yoshioka, 1964). The reproductive timing may be driven by environmental cycles, including seasonal cycles (Yamahira, 2004). In Java sea the first seasonal reproductive activity of the redbelly yellowtail fusilier began after the changing of monsoon from rainy to dry between April and May (Fig. 5). Hence, it is suggested that seasonal changing from rainy to dry affect the initiation of reproductive activity of the redbelly yellowtail fusilier in the tropical area.

From the histological observation, it was clear that the red-bellied yellowtail fusilier had three peak spawning season: in June-July, October-November and February-March. It seemed that they had specific patterns of reproductive activity by turns from active for two months to reducing the activity also for two months. While reducing the activity, sometimes they turned to minor spawning season (in August-September) or to off season (in May and December). During the peak season, advance developed oocytes could be found in all the ovaries, as the evidence that advance stage of Migratory and Maturation stages occupied large space of ovaries in June-July (Fig. 4a) while of Tertiary yolk stage occupied large space of ovaries 


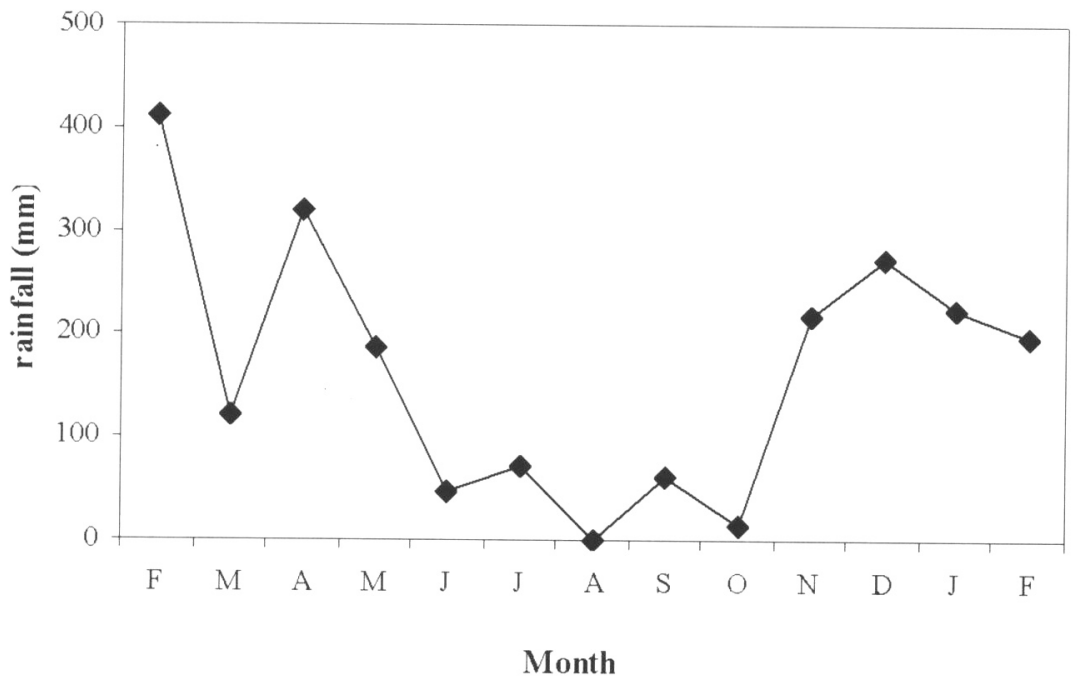

Figure 5. Monthly changes in the rainfall around Java Sea.

in October-November (Fig. 4b). In contrast, early stages of oocyte, PN stage, dominated the ovary space in some ovaries in September, reflecting the minor spawning occurred (Fig. 4c). It showed that recruitment of latest stage oocytes was considerably fall after two months periods of peak season, maintained in very low level until August or until September in some fishes. Clifton (1995) discovered temporal connection between adult food levels and reproductive output in striped parrotfish in Caribbean coral reef, where food availability for the adult was the primary determinant of their seasonal reproduction. As red-bellied yellowtail fusilier feed on zooplankton (Froese and Pauly, 2006), further study on seasonal planktonic conditions would beneficial for spatial and temporal reproductive activity understanding of this species.

Acknowledgements. This study was supported by a Grant-in-Aid for Scientific Research (B) (15405029) from Japan Society for the Promotion of Science (JSPS) for A.T. We would like to thank Michael Arvedlund, $\mathrm{PhD}$. for proofreading on this manuscript.

\section{REFERENCES}

Amiri, B.M., M. Maebayashi, H. Hara, S. Adachi, and K. Yamauchi. 1996. Ovarian development and serum sex steroid and vitellogenin profiles in the female cultured sturgeon hybrid, the bester. Journal of Fish Biollogy, 48: 164-1178.
Anonymous. 1996. FAO yearbook. Fishery statistics Capture production. Rome: FAO 8.

Arara, B.K., and M.J. Ntiba 1997. The reproductive biology of Lutjanus fulviflamma (Forsskal, 1775) (Pisces: Lutjanidae) in Kenyan inshore marine waters. Hydrobiologia, 353: 153-160.

Arocha, F. 2002. Oocyte development and maturity classification of swordfish from the nort-western Atlantic. Journal of Fish Biology, 60: 13-27.

Asoh, K. 2004. Gonadal development in the coral reef damselfish Dascyllus flavicaudus from Moorea, Frech Polynesia. Marine Biology, 146: 167-179.

Carpenter, K.E. 1988. FAO species catalogue Vol. 8. Fusilier fishes of the world. An annotated and illustrated catalogue of caesionid species known to date. FAO Fisheries Synopsis, 8(125): 75p.

Choi, C.Y., A. Takemura, and K. Takano. 1996. Ovarian development and changes in serum vitellogenin during the annual reproductive cycle of the female fusilier, Caesio diagramma. Galaxea, 13: 35-45.

Clifton, K.E. 1995. Asynchronous food availability on neighboring Caribbean coral reefs determines seasonal pattern of growth and reproduction for the herbivorous parrotfish Scarus iserti. Marine Ecology Progress Series, 116: 39-46.

Coward, K., and N.R Bromage. 1998. Histological classification of oocyte growth and the dynamics of ovarian recrudescence in Tilapia zillii. Journal of Fish Biology, 53: 285-302

DeMartini, E.E., and B.B. Lau. 1998. Morphometric criteria for estimating sexual maturity in two snappers, Etelis carbunculus and Pristipomoides sieboldii. Fishery Bulletin, 97: 449-458. 
Ferreira, B.P. 1993. Reproduction of the inshore coral trout Plectropomus maculates (Perciformes: Serranidae) from the Central Great Barrier Reef, Australia, Journal of Fish Biology, 42: 831-844.

Forberg, K.G. 1982. A histological study of development of capelin, Mallotus villosus (Muller). Journal of Fish Biology, 20: 143-154.

Froese, R., and D. Pauly. 2006. FishBase. World Wide Web electronic publication. www.fishbase.org, version $(05 / 2006)$.

Jackson, M.W., D.L. Nieland, and J.H. Cowan. 2006. Diel spawning periodicity of red snapper Lutjanus campechanus in the northern Gulf of Mexico. Journal of Fish Biology, 68: 695-706.

Mayer, I., S.E. Shackley, and J.S. Ryland. 1988. Aspects of the reproductive biology of the bass, Dicentrarchus labrax L. I. An histological and histochemical study of oocyte development. Journal of Fish Biology, 33: 609-622.

Tyler, C.R., J.P. Sumpter, and P.M. Cambel. 1991. Uptake of vitellogenin into oocytes during erly vitellogenic development in the rainbow trout,
Oncorhynchus mykiss (Walbaum). Journal of Fish Biology, 38: 681-689.

Tyler, C.R., and J.P. Sumpter. 1996. Oocyte growth and development in teleosts. Reviews in Fish Biology and Fisheries, 6: 287-318.

Wallace, R. A., and K. Selman. 1981. Cellular and dynamic aspects of oocyte growth in teleost. American Zoologist, 21: 325-343.

Yamahira, K. 2004. How do multiple environmental cycles in combination determine reproductive timing in marine organism? A model and test. Fuctional Ecology, 18: 4-15.

Yamamoto, K., and H. Yoshioka, 1964. Rhythm of development in the oocyte of the medaka, Oryzias latipes. Bulletin of the Faculty of Fisheries, Hokkaido University 11 (1): 5-19.

Yamamoto, K., and F. Yamasaki, 1961. Rhythm of development in the oocyte of the gold-fish, Carrassius auratus. Bulletin if the Faculty of Fisheries, Hokkaido University, 12: 93-110. 